\title{
Production of Granulocyte-Macrophage Colony-Stimulating Factors (GM-CSF) by Various Mammalian Cell Lines Cultured in a Protein-Free Synthetic Medium
}

\author{
Kazuko Tsuneoka and Mikio Shikita \\ National Institute of Radiological Sciences, Anagawa 4-chome, Chiba-shi \\ 260, Japan
}

\begin{abstract}
Thirteen cell lines, all of which had been adapted to grow in a chemically defined medium, produced colony-stimulating factor (CSF), but the production rates of the factor varied considerably among the cell lines. Rat liver parenchymal, monkey kidney, and rat spleen plasma cell lines were comparable to L.P3 cells in their CSF-producing activity. Isoelectrofocusing and gel-filtration chromatography in the presence of $6 \mathrm{M}$ guanidine $\mathrm{HCl}$ showed that the CSFs of the liver and kidney cell lines resembled L.P3 CSF, whereas the CSF of spleen cells differed from the other CSFs in its molecular properties. In addition, the CSF of the spleen cell line predominantly stimulated the formation of granulocytic colonies, but the L.P3 CSF and other CSFs mainly enhanced monocytic colony formation.
\end{abstract}

Myeloid stem cells themselves do not proliferate spontaneously, when they are isolated from hematopoietic tissues and dispersed in a medium supplemented with essential nutrients and serum. A specific glycoprotein, called colony-stimulating factor (CSF), is required for them to proliferate (11). In the absence of this factor, the stem cells cannot even survive under the culture conditions (10). The activity of CSF has been detected in various tissue extracts (17) as well as in media conditioned against cells of various organs (13) or against various cultured cell lines $(3,14,16,18)$. Because it exists in a number of sources, the specificity of its action as a regulator of the proliferation of myeloid stem cells has been doubted $(8,15)$. Recent reports on its inefficacy in stimulating granulopoiesis in long-term cultures of bone marrow cells have raised further arguments about its role as a true granulopoietin $(2,24)$. This led us to examine the generality of this factor as a product of various mammalian cell lines which had been adapted to grow in a chemically defined medium. It has been speculated that a principle produced by these cells eventually stimulates the proliferation of myeloid stem cells as well as these cells themselves. However, the rate of production of CSF varies considerably from one cell line to another, and is seemingly unrelated to the growth rate of these cells in culture. We also report that there are two distinct types of CSF, one that predominantly produces granulocytes and another that predominantly produces monocytes.

Abbreviation: CSF, colony-stimulating factor; PEG, polyethylene glycol 4000 


\section{MATERIALS AND METHODS}

Cells. The cells have been maintained in a synthetic medium DM-160 (Kyokuto Pharmaceut. Industry, Tokyo) $(5,6,7,20)$ in the laboratory of Drs. Katsuta and Takaoka, Dokkyo University, School of Medicine, Tochigi. Routinely, the cells have been grown in a stationary culture at $37^{\circ} \mathrm{C}$ on the surface of slanted test tubes containing $1.5 \mathrm{ml}$ of the nutrient solution. The medium was conditioned against grown cells (approximately $10^{6}$ cells/tube) for 3 days then frozen and stored. In the preparative experiment, cells were grown in several tubes as above for 3 or 4 days. The conditioned medium was harvested repeatedly from the same cultures and pooled in the amounts of $120 \mathrm{ml}$ (L·P3), $30 \mathrm{ml}$ (JTC-25·P3), $33 \mathrm{ml}$ (RSP-2·P3) and $65 \mathrm{ml}$ (JTC-12.PC). Protein concentration of the cell-conditioned medium was determined by the method of Bradford (1) with Coomassie brilliant blue G 250 (Bio-rad, Richmond, CA) after dialysis of the medium against $0.15 \mathrm{M} \mathrm{NaCl}$ containing $5 \mathrm{mM} \mathrm{Na}$ phosphate (pH 7.4) and $0.05 \%$ polyethylene glycol (PEG).

Chromatography and isoelectrofocusing. In the preparative experiment, the cell-conditioned medium was concentrated and dialyzed against $0.05 \%$ PEG, then centrifuged at $3,000 \mathrm{rpm}$ for $15 \mathrm{~min}$ to remove precipitates, after which it was isoelectrofocussed in a $20-\mathrm{ml}$ glass tube as reported previously (22). A sample of the focused CSF was treated with neuraminidase $(2 \mu \mathrm{g} / \mathrm{ml})$ for $3 \mathrm{~h}$ at $37^{\circ} \mathrm{C}$ in $0.1 \mathrm{M}$ acetate buffer at $\mathrm{pH} 5.5$. The CSF solutions, before and after the enzyme treatment, were mixed with appropriate amounts of solid guanidine $\mathrm{HCl}$ and then dialyzed against a large volume of $6 \mathrm{M}$ guanidine $\mathrm{HCl}$ containing $0.15 \mathrm{M}$ $\mathrm{NaCl}$ and $5 \mathrm{mM}$ Na phosphate (pH 7.4). A portion $(0.5 \mathrm{ml})$ of each CSF solution was applied to a Toyo-Pearl HW 55F column $(0.9 \times 60 \mathrm{~cm})$, which had been equilibrated with the guanidine solution. Twelve-drop fractions (about $0.38 \mathrm{ml}$ ) were collected at a rate of $2 \mathrm{ml} / \mathrm{h}$. Guanidine was removed from the eluate by dialysis.

The gel-filtration column was calibrated with standard proteins, which were run separately as above. Blue dextran and cytochrome $c$ were added to each run of the CSF solution as internal standards.

Assay of CSF activity. The CSF assay was the same as reported previously (21). Briefly, femoral marrow cells of male $\mathrm{C} 3 \mathrm{H}$ mice (aged about 3 months) were cultured for a week in McCoy's 5A medium containing $0.32 \%$ agar, $20 \%$ horse serum, and various amounts of CSF. The initial cell density was $1 \times 10^{5} /$ dish. One unit of CSF represents one colony in the culture. The colonies produced were counted under a magnification of 40. Some cultures were treated with $30 \%$ acetic acid in ethanol and washed 3 times with decreasing concentrations of aqueous ethanol according to the method described by $\mathrm{Wu}$ and Yunis (25). The contracted agar layers were removed intact from the petri dishes and transferred to glass plates, and dried thoroughly at $37^{\circ} \mathrm{C}$. Cells embedded in the thin film of dried agar were then stained with hematoxylin and examined microscopically at 200x magnification. Granulocyte colonies were distinguished easily from monocyte colonies by the size of the cells and by the characteristic doughnut- or horseshoe-like shape of the cell nucleus. Colonies containing both granulocytes and monocytes (mixed type colonies) were less than $20 \%$ of the total number and were included in the count of granulocytic colonies.

\section{RESULTS AND DISCUSSION}

Production of CSF by various mammalian cell lines growing in a protein-free synthetic medium. The results of the present study show that all the cell lines adapted to grow in a protein-free medium produced $\operatorname{CSF}(\mathrm{s})$, although the rate of production of the factor(s) varied markedly among the lines (Table 1). Unlike the macrophage growth 
TABle 1. Production of CSF by Mammalian Cell lines GROWING IN A PROTEIN-FREE MEDIUM

\begin{tabular}{lcc} 
& \multicolumn{2}{c}{ Dialyzed cell-conditioned medium } \\
\cline { 2 - 3 } Cell line & Protein $(\mu \mathrm{g} / \mathrm{ml})$ & CSF (units $/ \mathrm{ml})$ \\
\hline JTC-21·P3 (rat liver parenchymal cells) & 100 & $330^{\mathrm{a}}$, \\
JTC-23·P3 ( & 3 & 760 \\
JTC-25·P3 ( & 1 & $550(3000)^{\mathrm{b}}$, \\
JTC-16·P3 (rat ascites hepatoma cells) & 6 & 30 \\
JTC-12·P3 (monkey kidney cells) & 24 & $615(1140)$ \\
MDCK·P3 (dog kidney cells) & 47 & 45 \\
MDBK·P3 (bovine kidney cells) & 5 & 15 \\
L·P3 (mouse fibroblasts) & 4 & $1100(3625)$ \\
L·P3 Co-3 (60.Co resistant substrain of L·P3) & 24 & 1200 \\
RLC-10·P3 (normal rat liver cells) & 16 & 80 \\
M.P3 (rat liver cells) & 9 & 70 \\
RSP-2·P3 (rat spleen plasma cells) & 58 & $500(1100)$ \\
HeLa·P3 (human uterus carcinoma cells) & 3 & 20
\end{tabular}

a Average of three assays. There was no spontaneous colony formation under the assay conditions used.

b Figures in parentheses represent the CSF activity obtained in the preparative experiment.

factor (9), the CSFs showed no significant species specificity. For example, both rat and monkey cell lines produced CSF, which apparently was active on mouse bone marrow cells. There was no organ specificity, either. All the cells of liver, kidney, and spleen origin produced CSF. We did note that RLC-10.P3 and M.P3 cells were much less active than JTC-21·P3, JTC-23·P3 and JTC-25·P3 cells, although all these cell lines were derived from rat liver. The gross amounts of protein accumulated in the medium varied considerably in different cell lines and under different culture conditions, but the amount of CSF produced did not always increase proportionally to the total amount of protein.

The readiness of cells to adapt to serum-free conditions was not reflected directly by their ability to produce CSF. According to Katsuta and Takaoka (6), a period of several months was required for the L-929 cells to adapt to the protein-free milieu, whereas JTC-21 and JTC-25 cells grew rapidly as soon as they were transferred to the synthetic medium. In addition, culturing the cells in a protein-free medium was not a necessary condition for CSF production. The addition of $10 \%$ calf serum to the L.P3 cell culture did not abolish CSF production, but rather enhanced it significantly (data not shown).

Molecular properties of the produced CSFs. Of the thirteen cell lines examined, L·P3, JTC-25·P3, RSP-2·P3, and JTC-12·P3 cells were arbitrarily chosen for detailed studies of the properties of their CSFs. Isoelectrofocusing showed that the CSFs of the JTC-25.P3 and JTC-12·P3 cell lines were as strongly acidic as the CSF of L·P3 cells (Fig. 1), suggesting that these CSFs are sialoglycoproteins as the CSFs from various sources $(13,19,21)$. However, the CSF of RSP-2.P3 cells was slightly less acidic than the CSFs of the other three cell lines (Panel C of Fig. 1).

Because the presence of sialic acid residues in the molecule has been reported to cause CSF to behave abnormally in gel-filtration chromatography even in the presence 


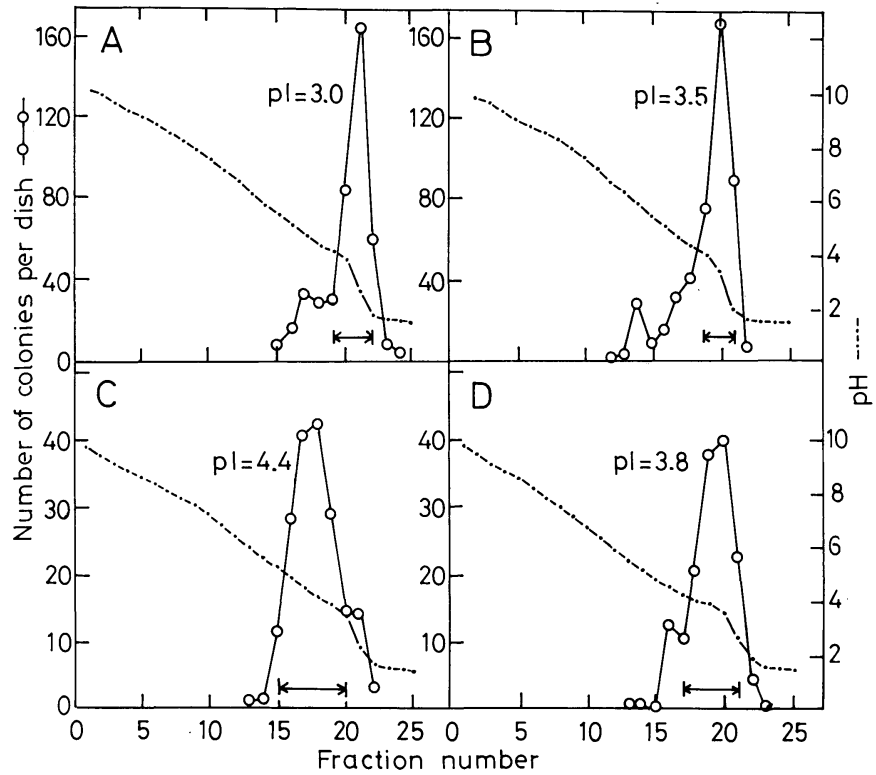

Fig. 1. Isoelectrofocusing of the CSFs of L·P3 cells (Panel A), JTC-25·P3 cells (Panel B), RSP-2·P3 cells (Panel C), and JTC-12.P3 cells (Panel D). CSF activity was determined in duplicate in the presence of material corresponding to 1-10 $\mu \mathrm{l}$ of each fraction. Horizontal arrows show that these fractions were combined and further processed for gel-filtration chromatography with guanidine $\mathrm{HCl}$. Recovery of CSF activity was about $80 \%$ on the average.

of $6 \mathrm{M}$ guanidine $\mathrm{HCl}$ (13), all four of the above species of CSF were desialylated with neuraminidase before their molecular weight was estimated by the gel-filtration chromatography method. It was thus revealed that three of the four CSFs resembled mutually; i.e., the CSFs of L·P3, JTC-12.P3 and JTC-25.P3 cells all were eluted at 1.35 void volumes, which corresponded to a molecular weight of 40,000 (Fig. 2). When the L·P3 and JTC-25·P3 CSFs were subjected to gel-filtration chromatography without treatment with neuraminidase, both CSFs were eluted at 1.33 void volumes (molecular weight, 47,000) (not shown). In contrast, the majority of the CSF activity of the RSP-2.P3 cells was eluted at 1.45 void volumes (molecular weight, 20,000) (Panel C of Fig. 2). Clearly, the CSF of RSP-2.P3 cells differs from the other three CSFs in both its molecular weight and its molecular charge.

The molecular weight of L.P3 CSF reported here is not consistent with the molecular weight of L60T CSF reported by others $(18,23)$, although both the L·P3 and L60T cell lines originally were derived from L cells. This discrepancy may simply be due to differences in the methods used to estimate the molecular weight in the different studies.

Morphology of the cells produced. When cultured marrow cells were fixed and stained in situ in agar then examined microscopically, granulocytes could be distinguished from monocytes. Thus, we found that the CSF of spleen cell line RSP-2.P3 differed from the CSFs of the other cell lines not only in its molecular properties but also in the granulocyte/monocyte ratio produced. The RSP-2.P3 CSF mainly produced granulocytic colonies, but the other CSFs mainly produced monocytic colonies. Examination of the gel-filtration fractions on both sides of the peak position gave no 


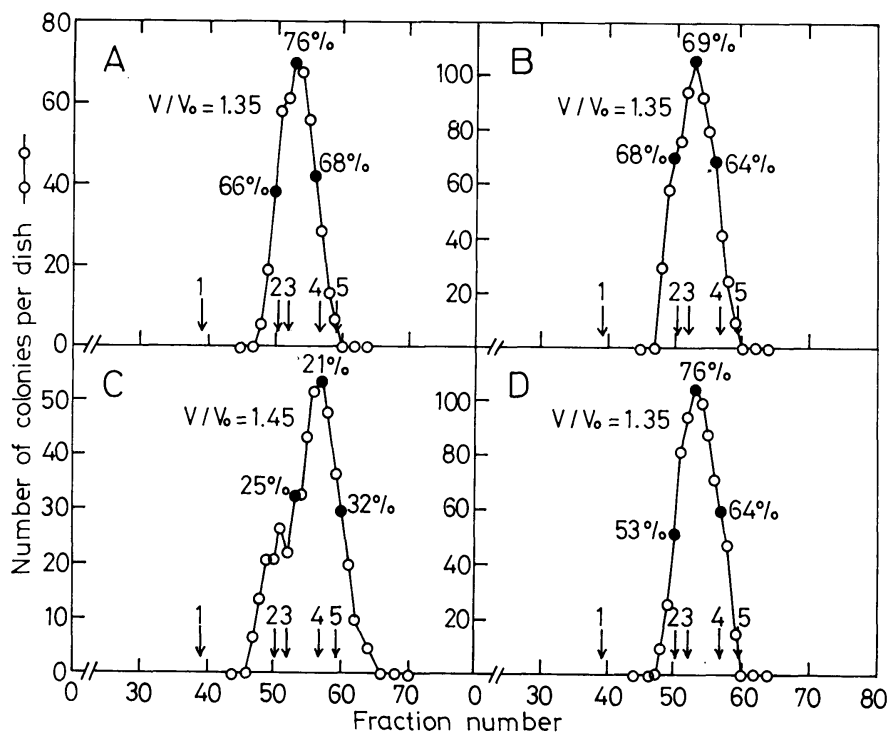

Fig. 2. Gel-filtration chromatography of partially purified CSFs in the presence of $6 \mathrm{M}$ guanidine $\mathrm{HCl}$. Panels A-D correspond to Panels A-D in Fig. 1. Each point represents the average of duplicate assays with $150-\mu$ l portions of the material (each fraction, dialyzed and diluted to $2 \mathrm{ml}$ ). Arrows $1-5$ indicate the elution positions of blue dextran, bovine serum albumin, egg albumin, chymotrypsinogen, and cytochrome C, respectively. Recovery of CSF activity was about $70 \%$ on the average. The top fractions and two bilateral fractions (closed circles) from each chromatography were assayed simultaneously for colony morphology. The percentages of monocytic colonies are shown as the average of 2 dishes. The percentage within each group varied by about one-tenth of the mean value.

indication of separation of the ganulopoietic from the monocytopoietic factor. The increase in CSF concentration tended to enhance the selective action of both types of CSF (Fig. 2; e.g., Panel A, Fraction No. 53 versus Fractions No. 50 \& No. 56, or Panel C, Fraction No. 57 versus Fractions No. 53 \& No. 60). As the report of Horiuchi and Ichikawa (4) that the factors specific for monocytopoiesis and for granulocytopoiesis were separable by gel-filtration, our present results suggest that there are two distinct types of granulocyte-macrophage CSF (GM-CSF) which significantly differ in the magnitude of amphibiousness, one producing granulocytic colonies, the other producing monocyte-macrophage ones.

Possibly the 7-day-old culture still contained semi-differentiated progenitor cells. Therefore the magnitude of amphibiousness mentioned above should be studied in detail in cultures of various age.

Acknowledgements. We thank Dr. B. Tamaoki, the Head of the Department of Pharmaceutical Science of our Institute, for his interest and encouragement during this study. We also sincerely thank Dr. H. Katsuta and Dr. T. Takaoka of Dokkyo University for the supply of cells and the cell-conditioned medium and for their valuable suggestions. This work has been supported by a grant-in-aid from the Science and Technology Agency of the Japanese Government.

\section{REFERENCES}

1. BRADFORD, M. M. A rapid and sensitive method for the quantitation of microgram quantities 
of protein utilizing the principle of protein-dye binding. Anal Biochem. 72, 248-254, 1976

2. Dexter, T. M. and R. K. Shadduck. The regulation of haemopoiesis in long-term bone marrow cultures: I. Role of L-cell CSF. J. Cell. Physiol. 102, 279-286, 1980

3. Guez, M. and L. SACHS. Purification of the protein that induces cell differentiation to macrophages and granulocytes. FEBS Lett. 37, 149-154, 1973

4. Horiuchi, M. and Y. ICHIKAWA. Control of macrophage and granulocyte colony formation by two different factors. Exp. Cell Res. 110, 79-85,1977

5. Katsuta, H. and T. TakaOKa. Cytobiological transformation of normal rat liver cells by treatment with 4-dimethylaminoazo-benzene after Nagisa culture. in Cancer Cells in Culture, ed. H. Katsuta, Univ. of Tokyo Press, Tokyo, pp. 321-334, 1968

6. Katsuta, H. and T. Takaoka. Cultivation of cells in protein- and lipid-free synthetic media. in Methods in Cell Biology, ed. D. M. Prescott, Academic Press, New York, Vol. 6, Chapter 1, pp. 1-42, 1973

7. KatsutA, H. and T. TAKAOKA. Improved synthetic media suitable for tissue culture of various mammalian cells. in Methods in Cell Biology, ed. D. M. Prescott, Academic Press, New York, Vol. 14, Chapter 13, pp. 145-158, 1976

8. LORd, B. I., K. J. Mori, E. G. Wright and L. G. LaJTha. Proliferation regulators in haematopoietic cell populations. Blood Cells 3, 451-459, 1977

9. Mauel, J. and V. Defendi. Regulation of DNA synthesis in mouse macrophages. I. Sources, action and purification of the macrophage growing factor (MGF). Exp. Cell Res. 65, 33-42, 1971

10. Metcalf, D. Studies on colony formation in vitro by mouse bone marrow cells. II Action of colony stimulating factor. J. Cell Physiol. 76, 89-100, 1970

11. Metcalf, D. Regulation of granulocyte and monocyte-macrophage proliferation by colony stimulating factor (CSF): A review. Exp. Hematol. 1, 185-201, 1973

12. Metcalf, D. and M. A. S. Moore. Regulation of growth and differentiation in haemopoietic colonies growing in agar. in Haemopoietic Stem Cells, ed. G. E., Wolsteinholme Ciba Foundation Symposium 13, Associated Scientific Publishers, Amsterdam, pp. 157-182, 1973

13. Nicola, N. A., A. W. Burgess and D. Metcalf. Similar molecular properties of granulocytemacrophage colony-stimulating factors produced by different mouse organs in vitro and in vivo J. Biol. Chem. 254, 5290-5299, 1979

14. Ohno, T., M. Seki and M. Shikita. Colony-stimulating factors active on human bone marrow cells from a Yoshida sarcoma cell line. Blood 51, 911-918, 1978

15. Price, G. B. and E. A. McCulloch. Cell surfaces and the regulation of hemopoiesis. Seminars in Hematol. 15, 283-300, 1978

16. Ralph, P., H. E. Broxmeyer, M. A. S. Moore and I. Nakoinz. Induction of myeloid colonystimulating activity in murine monocyte tumor cell lines by macrophage activators and in a $\mathrm{T}$ cell line by Concanavalin A. Cancer Res. 38, 1414-1419, 1978

17. Sheridan, J. W. and E. R. Stanley. Tissue sources of bone marrow colony stimulating factor. J. Cell Physiol. 78, 451-460, 1971

18. Stanley, E. R. and P. M. Heard. Factors regulating macrophage production and growth. Purification and some properties of the colony stimulating factor from medium conditioned by mouse L cells. J. Biol. Chem. 252, 4305-4312, 1977

19. Stanley, E. R., T. R. Bradley and M. A. Sumner. Properties of the mouse embryo conditioned medium factor(s) stimulating colony formation by mouse bone marrow cells grown in vitro. J. Cell. Physiol. 78, 301-318, 1971.

20. Tsuboi, K., T. TAKAOKA and H. Katsuta. Comparative analysis of strain L-929 and its substrain L.P3 grown in a protein- and lipid-free synthetic medium. Japan. J. Exp. Med. 42, 361-376, 1972

21. Tsuneoka, K. and M. Shikita. A sialoglycoprotein stimulating proliferation of granulocytemacrophage progenitors in mouse bone marrow cell cultures. FEBS Lett. 77, 243-246, 1977

22. Tsuneoka, K. and M. Shikita. Secretion and partial degradation of granulocyte-macrophage colony-stimulating factor (GM-CSF) of mouse L·P3 cells. J. Cell. Physiol. 102, 333-341, 1980 
23. Waheed, A. and R. K. Shadduck. Purification and properties of L cell-derived colony-stimulating factor. J. Lab. Clin. Med. 94, 180-194, 1979

24. Williams, N. and A. W. Burgess. The effect of mouse lung granulocyte-macrophage colony stimulating factor and other colony stimulating activities on the proliferation and differentiation of murine bone marrow cells in long-term cultures. J. Cell. Physiol. 102, 287-295, 1980

25. WU, M.-C. and A. A. Yunis. Common pattern of two distinct types of colony-stimulating factor in human tissues and cultured cells. J. Clin. Invest. 65, 772-775, 1980

(Received for publication, November 10, 1980) 